\title{
Pós colheita do abacate 'Hass' submetido a radiação UV-C
}

\section{Postharvest of 'Hass' avocados submitted to UV-C radiation}

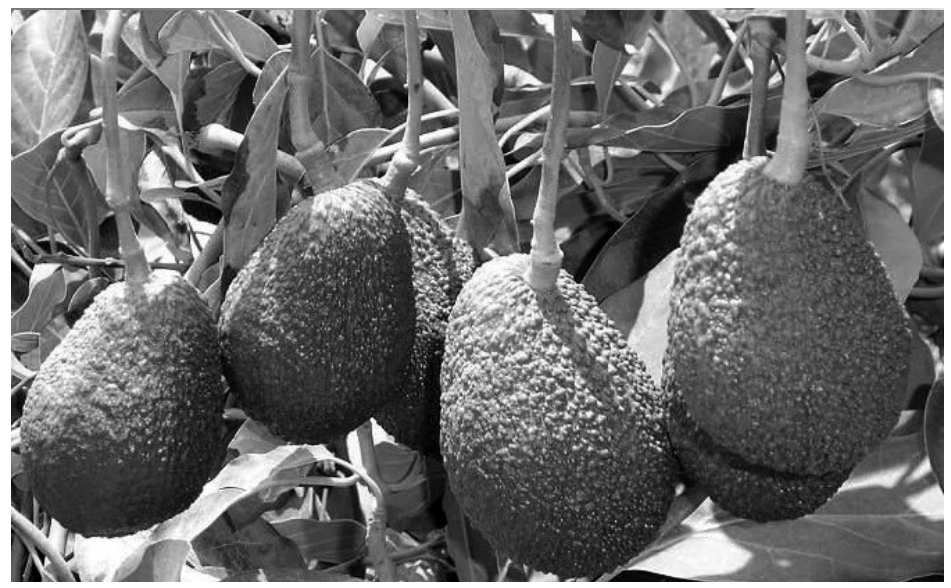

ÉRICA REGINA DAIUTO1, 5

ROGÉRIO LOPES VIEITES ${ }^{2}$

MARIA AUGUSTA TREMOCOLDI ${ }^{3}$

LIDIA RAQUEL DE CARVALHO 4

JOANA GIFFONI FIGUEIREDO FUMES ${ }^{3}$

Abacate 'Hass' em fructificação. Foto: Empresa Jaguacu, Bauru (São Paulo, Brasil)

\section{RESUMO}

Avaliou-se o efeito da radiação UV-C na conservação pós-colheita do abacate 'Hass'. Frutos selecionados foram submetidos à radiação em luz UV-C por $5,10,15$ e 20 minutos, mantidos sob refrigeração $\left(10 \pm 1^{\circ} \mathrm{C}\right.$ e $90 \pm 5 \%$ umidade relativa) e avaliados durante 15 dias. Determinou-se a perda de massa, taxa respiratória, acidez total titulável (ATT), sólidos solúveis totais (SST), ratio (SST/ATT), pH, firmeza, fenólicos totais e atividade antioxidante por $\mathrm{DPPH} \bullet$. A firmeza e o conteúdo de fenólicos totais diminuíram durante o período experimental nos frutos de todos os tratamentos. Houve correlação significativa moderada $(P=0,0 ; r=0,455)$ entre atividade antioxidante e compostos fenólico dos frutos. Os tratamentos cuja exposição a luz UV-C foi de 15 e 20 minutos apresentaram porcentagens de atividade antioxidante maiores em relação aos outros tratamentos, entre o 6 e 12 dias de armazenamento, perda de massa inferior ao tratamento controle e valores estáveis de sólidos solúveis durante o período experimental. Estes resultados apontam que a utilização da luz UV-C pode ser uma opção na conservação de abacate 'Hass'.

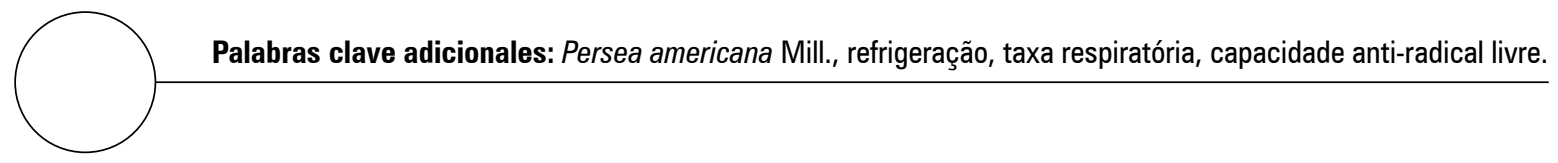

1 Programa de Pós-doutorado em Horticultura, CAPES/PNPD, Universidade Estadual Paulista - FCA/UNESP, Botucatu (Brasil).

2 Departamento de Horticultura, Facultade de Ciencias Agronomicas, UNESP, Botucatu (Brasil)

3 Programa de Mestrado em Horticultura, Universidade Estadual Paulista - FCA/UNESP, Botucatu (Brasil).

4 Departamento de Bioestadistica, Universidade Estadual de São Paulo - IB/UNESP, Botucatu (Brasil).

5 Autor para correspondência. erdaiuto@uol.com.br 


\section{ABSTRACT}

The effect of UV-C radiation on 'Hass' avocado postharvest conservation was evaluated. Selected fruits were submitted to UV-C radiation for $5,10,15$ or 20 minutes, refrigerated $\left(10 \pm 1^{\circ} \mathrm{C}\right.$ and $90 \pm 5 \%$ relative humidity), and evaluated for 15 days. Weight loss, respiratory rate, total titratable acidity (TTA), total soluble solids (TTS), ratio (TTS/TTA), pH firmness, total phenolics and antioxidant activity of DPPH $\bullet$ were evaluated. Firmness and total phenolic content decreased during the experimental period in fruits of all the treatments. There was a moderate, significant correlation $(P=0.0 ; r=0.455)$ between fruit antioxidant activity and total phenolic content. The treatments with UV-C light exposures of 15 and 20 minutes presented higher percentages of antioxidant activity when compared to the other treatments between the $6^{\text {th }}$ and $12^{\text {th }}$ days of storage; weight loss was lower than in the control treatment and soluble solids values were more stable during the experimental period. These results indicate that the use of UV-C light is an option for 'Hass' avocado conservation.

Additional key words: Persea americana Mill., refrigeration, respiratory rate, anti free radical scavenger activity.

Data de recepção: 09-01-2013

Aprovado para publicação: 31-10-2013
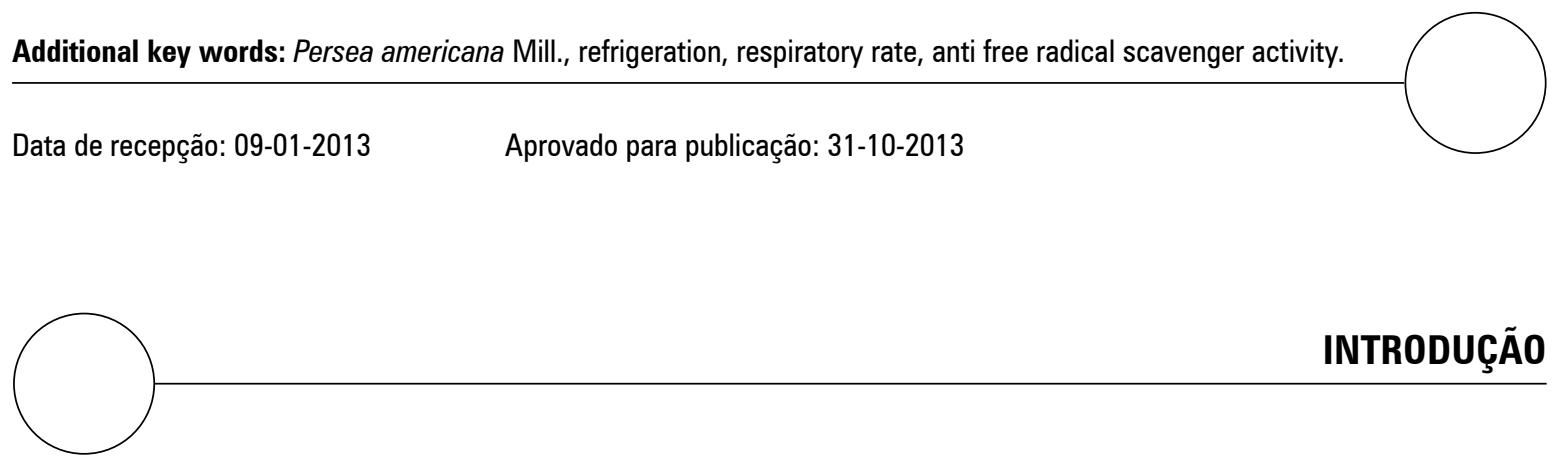

O abacate é fruto climatérico cujo amadurecimento ocorre poucos dias após a colheita (Hardenburg et al., 1986; Seymour e Tucker, 1993). A literatura aponta estudos relacionados ao aumento do período de conservação de abacate, como avaliação da temperatura de armazenamento, uso de atmosfera modificada com aplicação de cera, irradiação gama e tratamento térmico para prevenção de sintomas de injuria pelo frio (Zauberman et al., 1973; Castro e Bleinroth, 1982; Seymour e Tucker, 1993; Germano et al., 1996; Oliveira et al., 2000; Sanches, 2006; Morgado, 2007; Donadon, 2009).

O processo de irradiação utilizado na conservação de alimentos apresenta a vantagem de ser um método físico de tratamento. A irradiação ultravioleta (UV-C) é utilizada como método de controle de deterioração por resultar em desinfecção superficial de pequenos frutos, reduzindo o crescimento microbiano (Marquenie et al., 2003; Vicente et al., 2005; Khademi et al. 2013; Sricastava e Sharna, 2013), também segundo
Stevens et al. (2004) atrasa o amolecimento do fruto, um dos principais fatores determinantes na vida pós-colheita do fruto. Campos et al. (2011) relatam efeitos positiva da radiação UV-C sobre a qualidade dos tomates 'Pitenza'.

A qualidade pós-colheita dos frutos não está relacionada apenas aos parâmetros físicos e químicos avaliados, mas também com seu valor nutricional. Atualmente a qualidade para o consumidor está relacionada aos benéficos que o alimento pode trazer a sua saúde.

No estudo da qualidade pós-colheita de frutos, normalmente, são avaliados parâmetros como perda de massa, firmeza, ratio, vitaminas, $\mathrm{pH}$, acidez total titulável, coloração, atividades de enzima de escurecimento entre outros. Atualmente, a avaliação da capacidade anti radical livre tem sido importante para determinar a eficiência do antioxidantes naturais em relação à proteção do produto vegetal contra dano oxidativo e perda do valor comercial e nutricional. $\mathrm{O}$ abacate 
possui considerável qualidade nutritiva, com alto conteúdo de fibras, proteínas, sais minerais, destacando-se o potássio e vitaminas, especialmente a vitamina E (USDA, 2007), além de significativa quantidade de ácidos graxos insaturados com efeitos benéficos na prevenção de doenças cardiovasculares (Tango et al., 2004). Por ser uma fonte de ácidos graxos poli-insaturados, esta fruta deve possuir uma grande variedade de antioxidantes, dentre os quais compostos fenólicos, para proteção e integridade do óleo contra oxidação.

O abacate 'Hass' é bem aceito no mercado externo (EUA e Europa) e o comportamento dos frutos submetidos a radiação UV-C ainda não foi avaliado.

O objetivo desta pesquisa foi avaliar o efeito da radiação UV-C na conservação pós-colheita do abacate 'Hass'.

\section{MATERIAL E MÉTODOS}

Os frutos foram fornecidos pela empresa Jaguacy, localizada em Bauru/SP-Brasil, cujas coordenadas geográficas são: latitude $22^{\circ} 19^{\prime} 18^{\prime \prime} \mathrm{S}$, longitude $49^{\circ} 04^{\prime} 13$ " W e $526 \mathrm{~m}$ de altitude. Frutos de abacate 'Hass' cuidadosamente colhidos no ponto de maturação fisiológica e de acordo com o teor de óleo foram submetidos à luz ultravioleta (UV-C $\operatorname{com} \lambda=250 \mathrm{~nm}$ ), sendo a distância dos frutos à fonte de luz de $20 \mathrm{~cm}$ e o período de exposição de 5, 10, 15, 20 e 25 min, caracterizando 4 tratamentos. A exposição à radiação foi realizada em aparelho com luz UV (IRINOX, refrigerador e congelador, marca AREX, modelo: $\mathrm{n}-\mathrm{HCM}$ 51/20). Frutos não submetidos à exposição em luz UV-C caracterizaram o tratamento controle. Os frutos dos 5 tratamentos foram mantidos sob refrigeração $\left(10 \pm 1^{\circ} \mathrm{C}\right.$ e $90 \pm 5 \%$ UR).

Foram realizadas as seguintes análises: Perda de peso fresco determinado pela pesagem dos frutos em balança analítica, considerando a massa inicial de cada amostra, com os resultados expressos em percentagem.
Atividade respiratória determinada pela liberação de $\mathrm{CO}_{2}$ em cada embalagem, de acordo com metodologia adaptada de Bleinroth et al. (1976), utilizando-se para isso solução de hidróxido de bário saturado e solução de hidróxido de potássio $0,1 \mathrm{~N}$. A avaliação perda de massa e atividade respiratória foi avaliada durante $21 \mathrm{~d}$ e as demais análises foram até os $15 \mathrm{~d}$ de armazenamento.

Os teores de sólidos solúveis totais (SST), pH, acidez total titulável (ATT), umidade e lipídios foram determinados seguindo as Normas Análiticas do Instituto Adolfo Lutz (2008). O teor de sólidos solúveis foi medido, em leitura refratométrica em ${ }^{\circ}$ Brix, a $20^{\circ} \mathrm{C}$, com refratômetro digital, conforme metodologia. Foi determinado o ratio pela relação entre o teor de sólidos solúveis e acidez titulável (Tressler e Joslyn, 1961).

A avaliação firmeza foi feita utilizando-se texturômetro, com a distância de penetração de $20 \mathrm{~mm}$, velocidade de 2,0 $\mathrm{mm} \mathrm{s}^{-1}$ e ponta de prova TA 9/1000, os resultados foram apresentados em gramas/força. Foram realizadas 5 leituras para em cada uma das 3 repetições em todos os tratamentos.

O conteúdo de fenólicos totais foi determinado pelo método espectrofotométrico de Folin-Ciocalteau descrito por Singleton et al. (1999), utilizando ácido gálico como padrão. Os extratos obtidos foram transferidos para um tubo de ensaio, com uma alíquota de $0,5 \mathrm{~mL}$ e adicionado 2,5 mL do reagente Folin Ciocalteau, diluído em água 1:10. A mistura permaneceu em repouso por $5 \mathrm{~min}$. Em seguida foi adicionado $2 \mathrm{~mL}$ de carbonato de sódio $4 \%$ e os tubos deixados em repouso por 2 h, ao abrigo da luz. A absorbância foi medida em espectrofotômetro a $740 \mathrm{~nm}$. Uma amostra em branco foi conduzida nas mesmas condições. Os resultados expressos em $\mu \mathrm{g}$ GAE $100 \mathrm{~g}^{-1}$ de peso seco.

A capacidade antioxidante das amostras foi avaliada pelo DPPH • (2,2-diphenyl-1-picrylhydrazyl) segundo (Mensor et al., 2001). A atividade 
anti-radical foi determinada na forma de atividade antioxidante (AA), pela equação:

$\mathrm{AA}(\%)=100-((\mathrm{Aa}-\mathrm{Ab}) \times 100) / \mathrm{Ac}(1)$

donde: $\mathrm{Aa}=$ absorbância da amostra; $\mathrm{Ab}=$ absorbância do branco; $A c$ = absorbância do controle negativo. $O$ controle negativo foi feito substituindo-se o volume do extrato por igual volume do solvente utilizado na extração (etanol). O branco foi preparado substituindo o volume da solução de $\mathrm{DPPH} \bullet$ por igual volume de solvente

Os dados foram então submetidos à análise de regressão e correlação de Pearson.

\section{RESULTADOS E DISCUSSÕES}

A perda de massa fresca dos frutos (figura 1) foi crescente para todos os tratamentos durante o período experimental. Observou-se perda de massa mais acentuada nos frutos submetidos à radiação em luz UV-C por 5 min, principalmente após o 9 dia de armazenamento.

Para a maioria dos produtos hortícolas frescos, a máxima perda de massa fresca tolerada para o não aparecimento de murcha e/ou enrugamento da superfície oscila entre 5 e 10\% (Finger e Vieira, 2002) e produtos perecíveis como o abacate mesmo quando colocados em condições ideais, sofrem alguma perda de peso durante o armazenamento devido ao efeito combinado da respiração e da transpiração (Chitarra e Chitarra, 2005). Notou-se um aumento da perda de massa e da produção de $\mathrm{CO}_{2}$ (figura 2) nos frutos de todos tratamentos, portanto acelerando os processos metabólicos de degradação dos frutos. Nesta pesquisa a perda de massa não foi superior a $2,5 \%$ até o $12^{\circ}$ dia de armazenamento ou à $5 \%$ no período em estudo, conseqüência do armazenamento refrigerado. A redução da temperatura reduz drasticamente a respiração dos frutos, retardando o amadurecimento e, consequentemente, aumentando seu período de armazenamento.

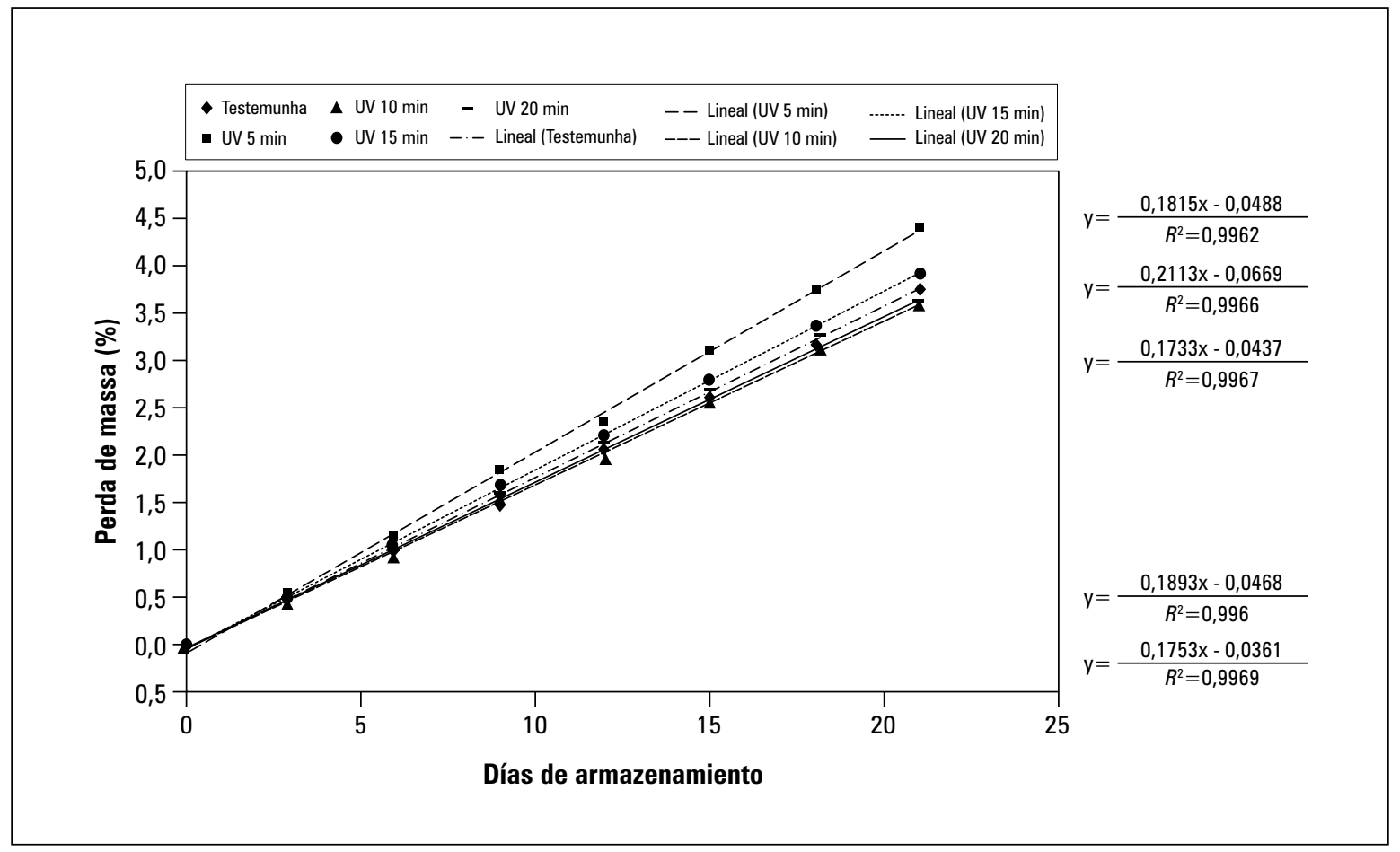

Figura 1. Percentual da perda de massa em abacate 'Hass' submetido à radiação UV-C e armazenado a $10 \pm 1^{\circ} \mathrm{C} e$ $90 \pm 5 \%$ UR. 
Observou-se para taxa respiratória, nos 5 tratamentos, o mesmo comportamento climatérico conforme já descrito para abacate (Seymour e Tucker, 1993; Daiuto et al., 2010a; Daiuto et al., 2010b). O pico respiratório ocorreu em torno do $12^{\circ}$ dia para os tratamentos controle e UV-C 5 min, aos 10 dias para o tratamento UV-C $10 \mathrm{~min}$ e aos $9 \mathrm{~d}$ nos tratamentos UV-C 15 e 20 min (figura 2).

Apesar do pico mais tardio para os tratamentos controle e UV-C 5 min, a produção de $\mathrm{CO}_{2}$ nestes frutos foi maior em relação aos demais, mostrando um possível efeito do tratamento UV-C na redução da atividade respiratória, sendo neste caso o tempo de exposição de 5 min não suficiente para trazer tal benefício na conservação dos frutos. Daiuto et al. (2010b) em avaliação da perda de peso e taxa respiratória de frutos de abacate 'Hass' submetidos a diferentes tratamentos físicos ( térmico a $45^{\circ} \mathrm{C}$, UV-C e radiação gama) e armazenados a $10^{\circ} \mathrm{C}$, obtiveram resultados in- dicativos da redução da taxa de produção de $\mathrm{CO}_{2}$ em relação aos frutos controle.

O conteúdo de ATT diminuiu ao longo do período de armazenamento, exceto para o tratamento UV-C por 20 min que apresentou aumento de valores até o $9^{\circ}$ dia de armazenamento. Conforme já relatado, a exposição durante 20 min a luz UV$\mathrm{C}$ também resultou em baixa produção de $\mathrm{CO}_{2}$ e perda de massa, suportando por tanto, a hipótese de maior conservação para estes frutos, já que a redução da acidez (figura 3) é decorrência natural da evolução da maturação dos frutos, na qual os ácidos orgânicos são metabolizados na via respiratória e convertidos em moléculas não -ácidas (Chitarra e Chitarra, 2005).

Os teores de SST do abacate mantiveram-se ao longo do período experimental para todos os tratamentos, exceto para o tratamento controle que atingiu ponto de máximo aos 3 a $6 \mathrm{~d}$ diminuindo de forma mais pronunciada em relação

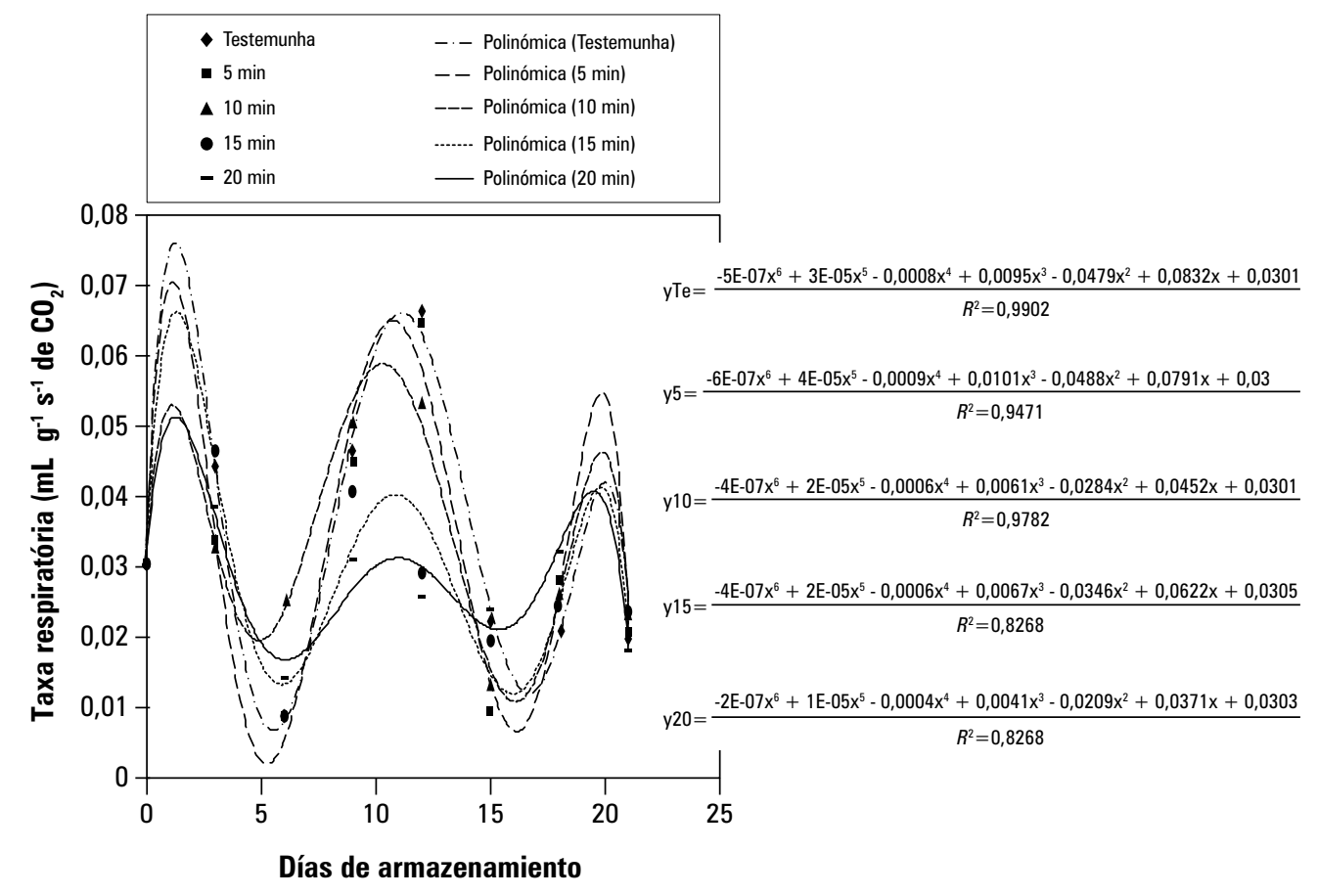

Figura 2. Atividade respiratória em abacate 'Hass' submetido à radiação UV-C submetido à radiação UV-C e armazenado a $10 \pm 1^{\circ} \mathrm{C}$ e $90 \pm 5 \%$ UR. 


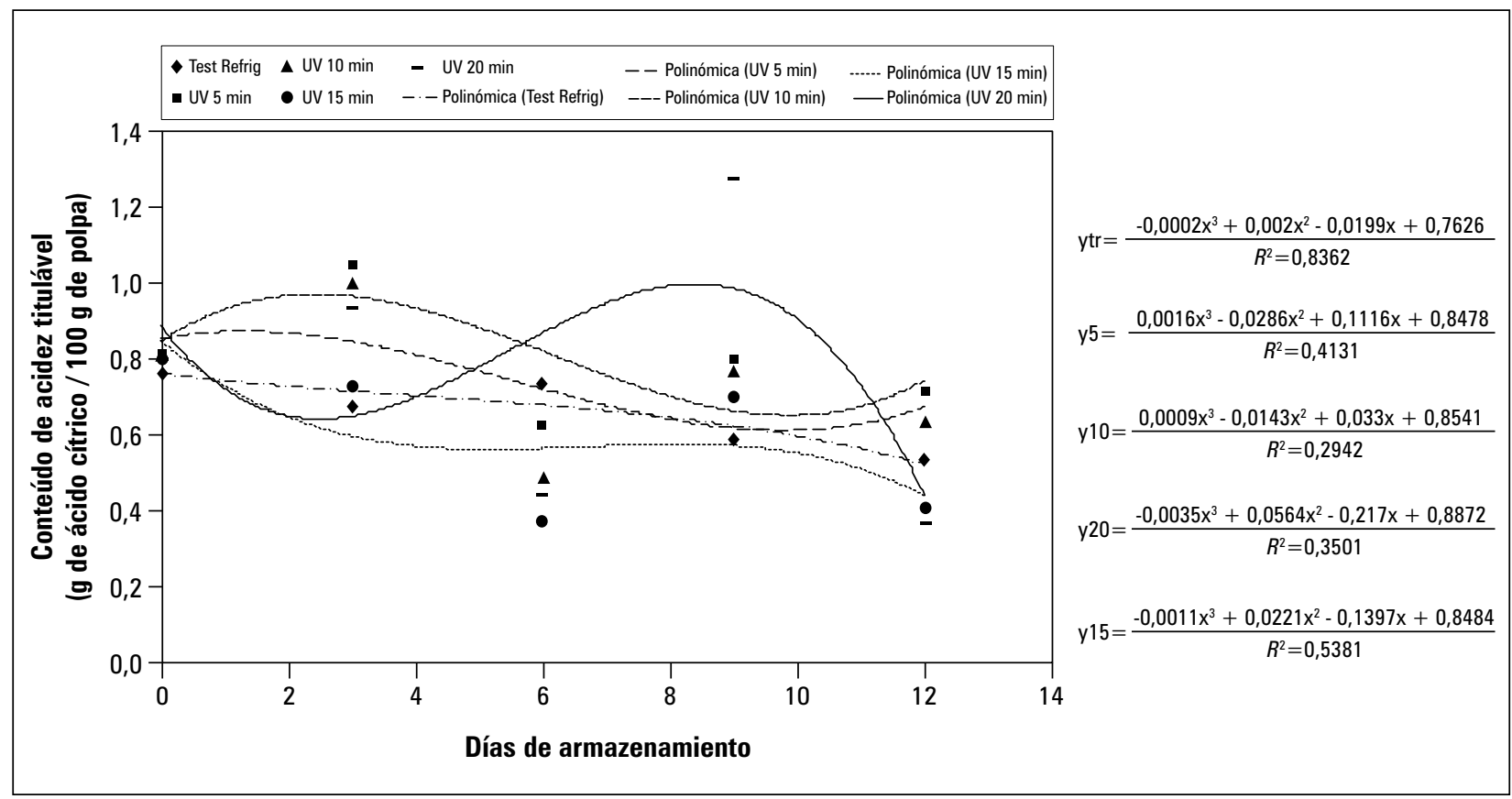

Figura 3. Conteúdo de acidez total titulável em abacate 'Hass' submetido a radiação UV-C e armazenado a $10 \pm 1^{\circ} \mathrm{C}$ e $90 \pm 5 \%$ UR.

aos demais tratamentos, após este período. Esta diminuição esta associada ao fato dos SST serem substrato energético para a transformação e sobrevivência pós-colheita. Essa informação pode ser verificada pelas equações da figura 4 . Este resultado mostra um processo de senescência adiantado do tratamento controle em relação aos demais tratamentos. Resultado semelhante foi observado por Khademi et al. (2013) e PerkinsVeazie et al. (2008) em estudos com caqui e mirtilo, respectivamente, e ambos submetidos ao tratamento com luz UV-C, que não observaram diferenças significativas para os teores de SST e ATT durante o armazenamento.

O ratio é a relação SST/ATT, sendo um parâmetro indicativo de amadurecimento e qualidade do fruto (Chitarra e Chitarra, 2005). Observou-se para este parâmetro relação inversa com a acidez total titulável, onde $(r=-0,77 \operatorname{com} P=0,000)$ (figura 5).

$\mathrm{O} \mathrm{pH}$ dos frutos de abacate dos 5 tratamentos aumentou durante o período de armazenamento (figura 6). Este resultado segundo Chitarra e Chitarra (2005) pode ter sido conseqüência da diminuição de acidez total titulável que ocorre normalmente em todos os frutos durante o amadurecimento. No entanto, Oliveira et al. (2000) e Daiuto et al. (2010b) encontram estabilidade nos valores de $\mathrm{pH}$ durante o armazenamento. Oliveira et al. (1996) não encontraram diferenças significativas para o $\mathrm{pH}$ em frutos da variedade Fuerte tratados com cera em temperatura ambiente e refrigerada, assim como Daiuto et al. (2010b) que observaram a mesma tendência relatada por estes autores em abacate 'Hass' e armazenado nas mesmas condições. Observa-se que a figuras 6 apresenta uma única equação, indicando que não houve diferença entre os tratamentos para este parâmetro.

Os frutos apresentaram uma redução da firmeza em relação os valores iniciais, principalmente até o $12^{\circ}$ dia de armazenamento, com um aumento após este momento. Este fato pôde ser constatado, conforme apresenta a equação da figura 7. Khademi et al. (2013) avaliando o efeito da radiação UV-C em caquis, também observaram redução dos valores de firmeza dos frutos durante o armazenamento. Em contraste a estes resultados 


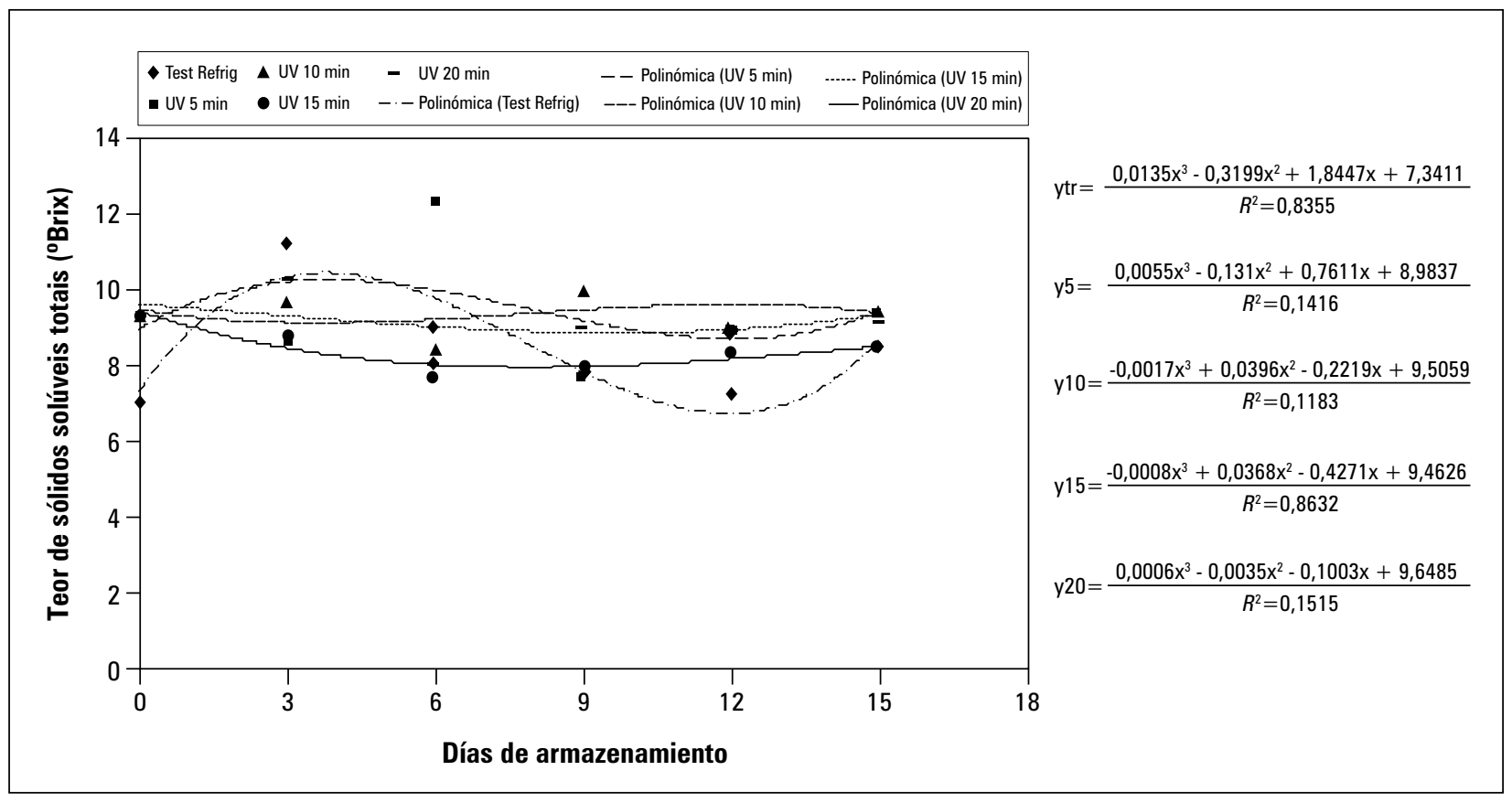

Figura 4. Sólidos solúveis totais em abacate 'Hass' submetido a radiação UV-C e armazenado a $10 \pm 1{ }^{\circ} \mathrm{C}$ e $90 \pm 5 \%$ UR.

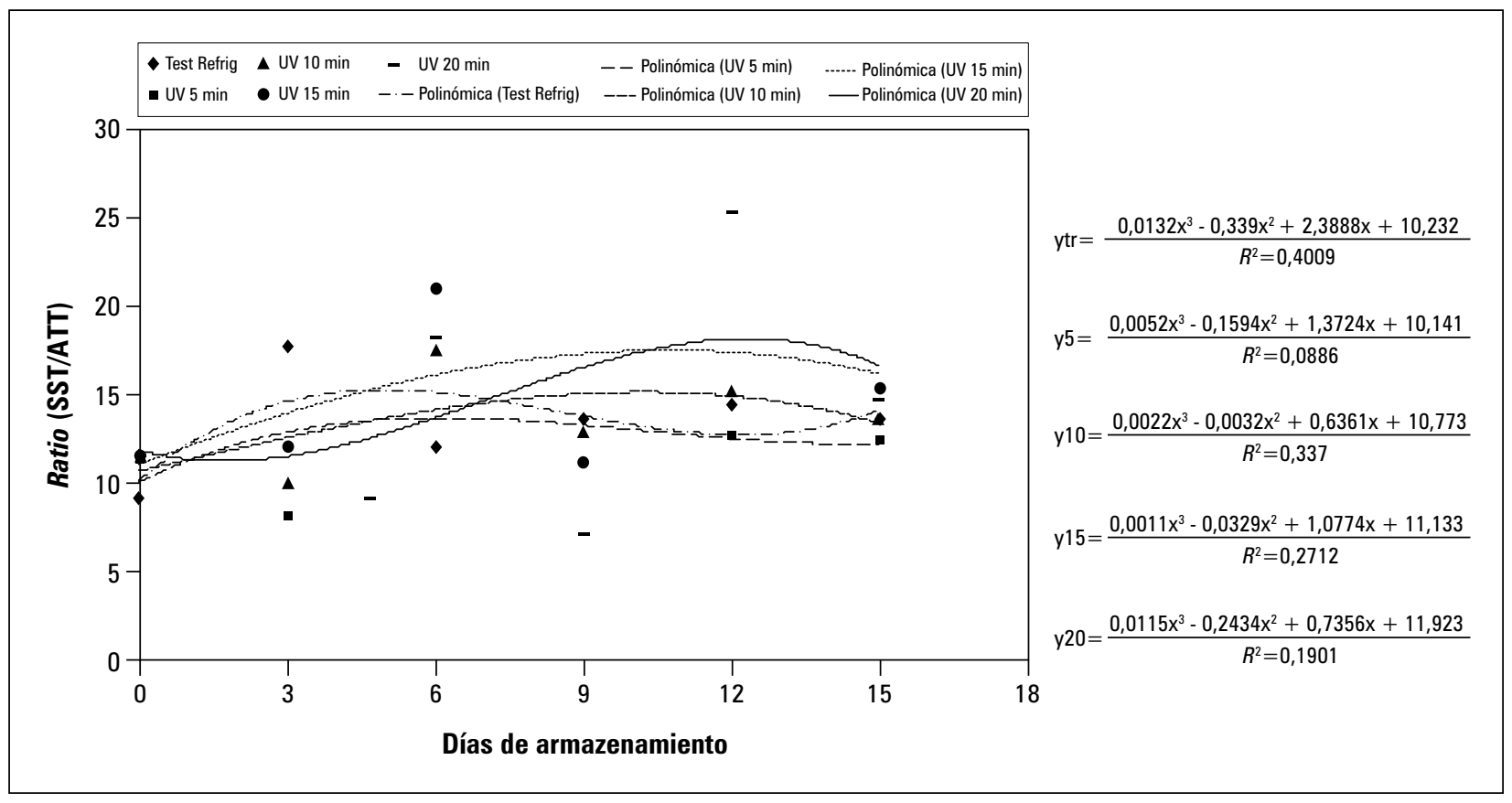

Figura 5. Ratio (SST/ATT) em abacate 'Hass' submetido a radiação UV-C e armazenado a $10 \pm 1^{\circ} \mathrm{C}$ e $90 \pm 5 \%$ UR. 


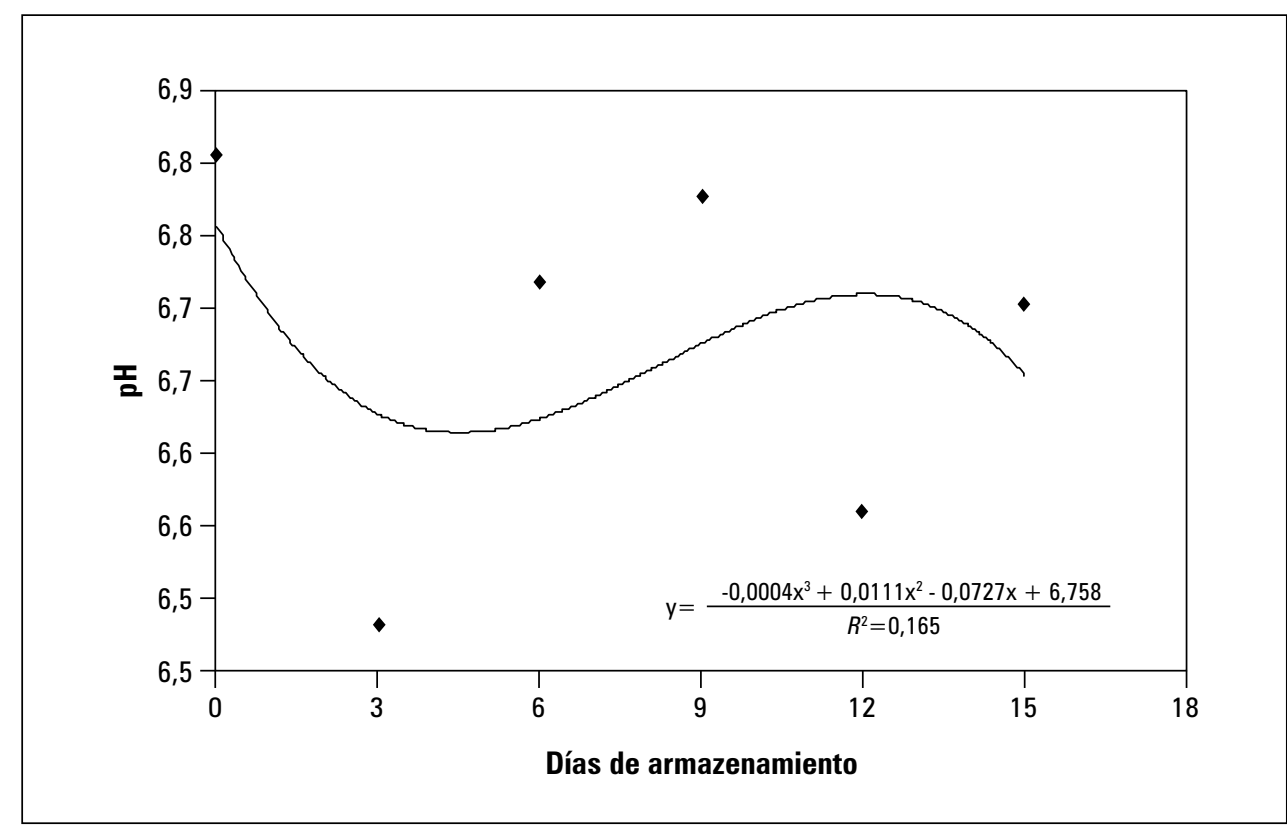

Figura 6. Potencial hidrogênionico em abacate 'Hass' submetido a radiação UV-C e armazenado a $10 \pm 1^{\circ} \mathrm{C}$ e $90 \pm 5 \%$ UR.

outros autores reportaram para tomate (Barka et al., 2000) e morango (Pombo et al., 2009) submetidos a luz UV-C, manutenção dos valores de firmeza superiores ao tratamento controle durante o armazenamento.

Para o conteúdo de compostos fenólicos totais obteve-se uma equação de regressão polinomial única (figura 8). Para média geral dos tratamentos obtevese os valores de 24,2; 23,1; 25,7; 25,9 e 21,2 $\mu \mathrm{g}$ GAE $100 \mathrm{~g}^{-1}$ respectivamente para o tratamento testemunha, 5, 10, 15 e 20 min exposição à luz UV-C.

Pode-se observar valores decrescentes ao longo do armazenamento para a atividade antioxidante determinada por DPPH $\bullet$ em todos tratamentos (figura 9). Para os tratamentos UV-C 15 e 20 min observou-se aumento da AA, no entanto com valores inferiores ao primeiro dia de análise. Entre o 6 e $12^{\circ}$ dias de armazenamento estes tratamentos mantiveram maiores porcentagens de AA, em relação aos demais tratamentos, decaindo a partir deste momento como conseqüência da senescência dos frutos. A média geral dos tratamentos mostrou os valores de $27,5 \%$; $23,8 \%$;
$24,3 \% ; 27,5 \%$ e $23,1 \%$ de atividade antioxidante respectivamente para o tratamento testemunha, 5, 10, 15 e 20 min exposição à luz UV-C. O valor mínimo obtido foi de 20,2 no ultimo dia de análise e o máximo de 32,1 para o tratamento testemunha no 1 dia de análise.

O conteúdo de componentes fenólicos totais não necessariamente está envolvido na quantificação da atividade antioxidante (Jacobo-Velasqués y Cisneros-Zevallos, 2009). Para atividade antioxidante e compostos fenólicos de abacate 'Hass' a análise de correlação mostrou-se uma correlação significativa, moderada, onde $P=0,0$ e $r=0,455$. Já Arancibia-Avila et al. (2008) encontraram uma correlação de 0,98 entre o conteúdo de compostos fenólicos e a capacidade antioxidante. Os autores concluíram que o alto teor de polifenois foi principal responsável pela capacidade antioxidante. Wang et al. (2010) encontram correlação significativa para o conteúdo de fenólicos totais e a AA $(r=0,79)$. Estes dois parâmetros avaliados pelos autores não correlacionaram com o conteúdo de clorofila e carotenóides $(r<0,01)$. Para os autores a alta correlação entre as procianidinas, o conteúdo 


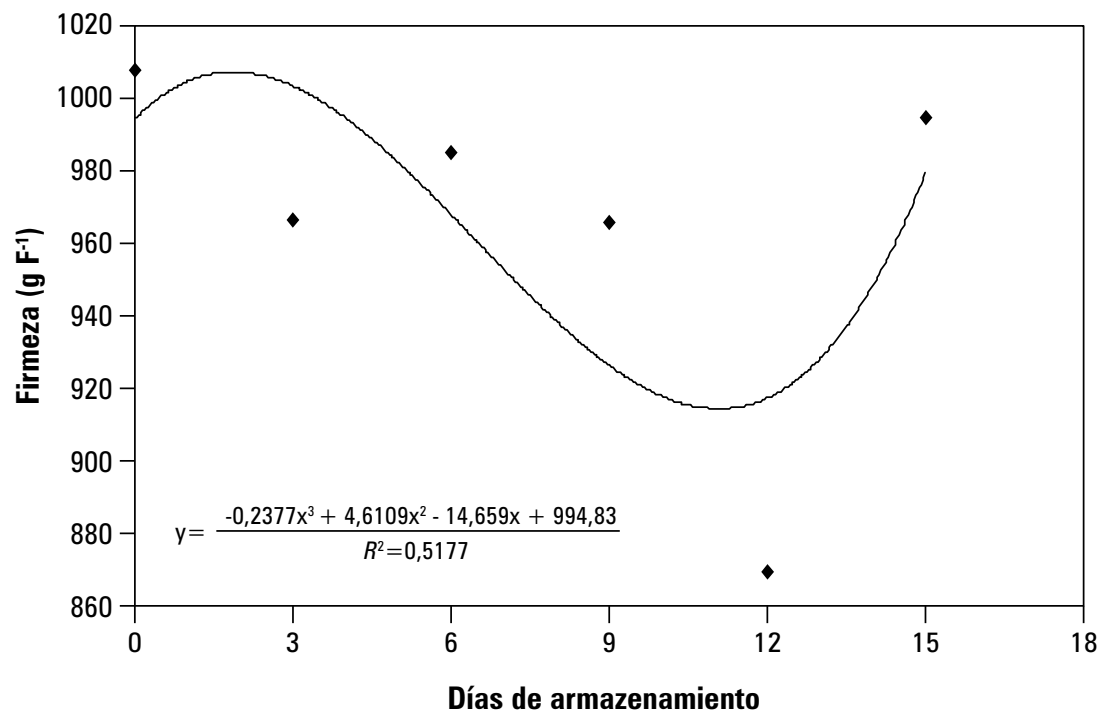

Figura 7. Firmeza em abacate 'Hass' submetido submetido à radiação UV-C e armazenado a $10 \pm 1^{\circ} \mathrm{C}$ e $90 \pm 5 \%$ UR

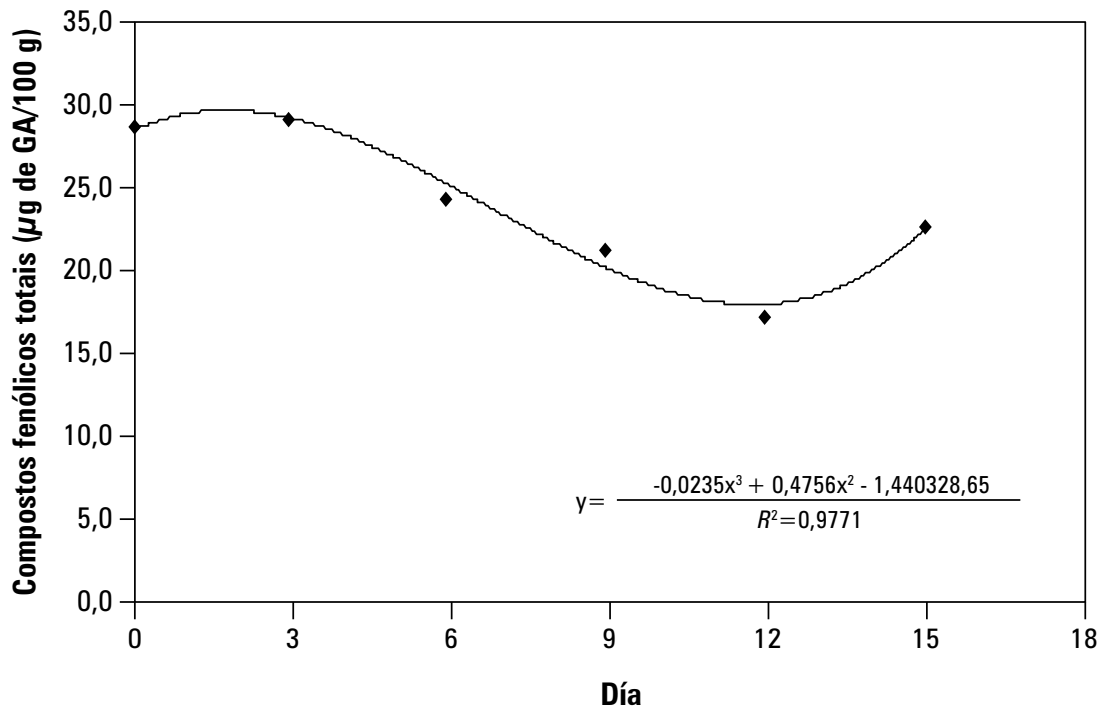

Figura 8. Compostos fenólicos totais em abacate 'Hass' submetido a radiação UV-C e armazenado a $10 \pm 1^{\circ} \mathrm{C}$ e $90 \pm 5 \%$ UR 


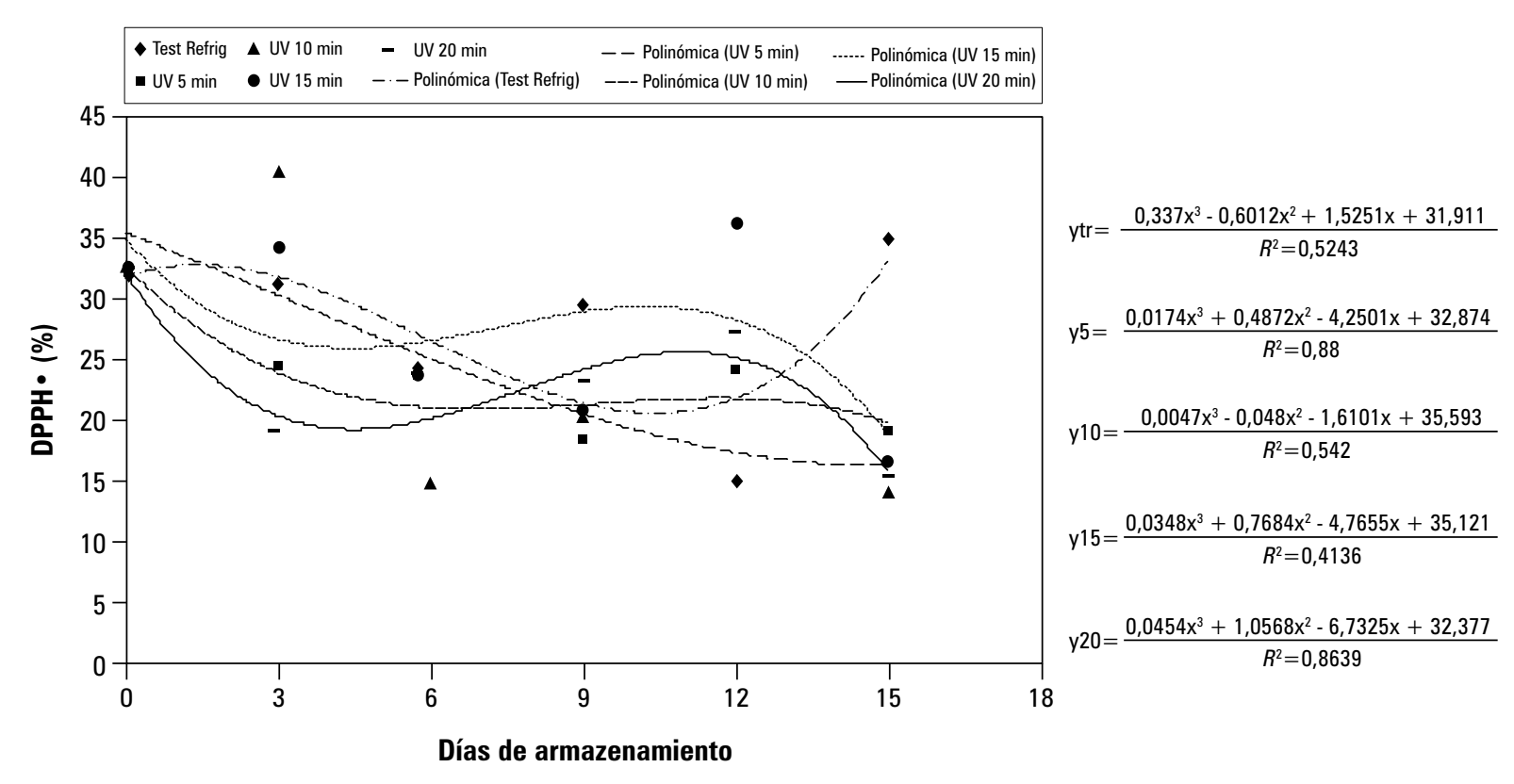

Figura 9. Atividade antioxidante DPPH• em abacate 'Hass' submetido a radiação UV-C e armazenado a $10 \pm 1^{\circ} \mathrm{C}$ e $90 \pm 5 \%$ UR

de polifenois e a atividade antioxidante sugere que este composto é o polifenol principal que contribui para a capacidade anti radical livre em abacate.

Vale ressaltar que a presença de outros compostos presentes no fruto, como a vitamina $\mathrm{E}$, devem ser avaliados, a fim de verificar sua contribuição para a atividade antioxidante no abacate.

\section{CONCLUSÕES}

Os tratamentos cuja exposição à luz UV-C foi de 15 e 20 min foram aqueles que mostraram resultados mais promissores para serem utilizados na conservação de abacates 'Hass', principalmente pelos resultados obtidos de perda de peso e atividade respiratória.

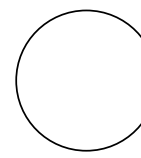

AGRADECIMIENTOS

À empresa Jaguacy (Bauru-SP) pelo apoio e participação nas pesquisas e à Coordenação de Aperfeiçoamento de Pessoal de Nível Superior (CAPES)

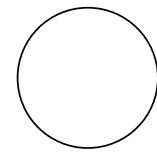

Arancibia-Avila, P., F.Toledo, Y.S. Park, S.T. Jung, S.G. Kang, B.G. Heio, S.H. Lee, M. Sajewicz, T. Kowalska e S. Gorintein. 2008. Antioxidant properties of durian fruit as influenced by ripening. Food Sci. Technol. 41, 2118-2125

\section{REFERENCIAS BIBLIOGRÁFICAS}

Barka, E. A., S. Kalantari, J. Makhlouf e J. Arul. 2000. Impact of UV-C irradiation on the cell wall-degrading enzymes during ripening of tomato (Lycopersicon esculentum L.) fruit. J. Agric. Food Chem. 48, 667-671. 
Bleinroth, E.W., A.G. Zuchini e R.M. Pompeo. 1976. Determinação das características físicas e mecânicas de variedade de abacate e sua conservação pelo frio. Coletânea ITAL 7(1), 29-81.

Campos, A.J., R.L. Vieites, L.C. Neves, P.A. Robles e F.A. Calero. 2011. Ultraviolet radiation (UV-C) in characterization postharvest of tomato 'Pitenza'. Rev. Iber. Tecnología Postcosecha 12(2), 192-198.

Castro, J.V. e E.W. Bleinroth. 1982. Conservação do abacate em atmosfera controlada e à temperatura ambiente. Boletim do Instituto de Tecnologia de Alimentos 19(2), 165-182.

Chitarra, M.I.F. e A.B. Chitarra. 2005. Pós-colheita de frutos e hortaliças: fisiologia e manuseio. Ed UFLA, Lavras, Brasil.

Daiuto, E.R, M.A. Tremocoldi e R.L. Vieites. 2010a. Conservação pós colheita de abacate 'Hass' irradiado. Rev. Iber. Tecnología Postcosecha 10(2), 94-100.

Daiuto, E.R, R.L. Vieites, M.A. Tremocoldi e V.C. Russo. 2010b. Taxa respiratória de abacate 'Hass' submetido a diferentes tratamentos físicos. Rev. Iber. Tecnología Postcosecha 10(2), 101-109.

Donadon, J.R. 2009. Distúrbio fisiológico provocado pelo frio e prevenção com tratamentos térmicos em abacates. Doutor em Agronomia. Faculdade de Ciências Agrárias e Veterinárias, Unesp, Jaboticabal, Brasil.

Finger, F.L. e G. Vieira. 2002. Controle da perda pós-colheita de água em produtos hortícolas. UFV, Viçosa, Brasil.

Germano, R. M.A., F.M.V. Arthur e F.M.Wiendl, 1996. Conservação pós-colheita de abacates Persea americana Mill., variedades Fortuna e Quintal, por irradiação. Sci. Agric. 53(2-3), 249-253.

Hardenburg, R.E., A.E. Watada e C.Y. Wang. 1986. The comercial storage of fruits, vegetables, and florist and nursery stocks. USDA, Beltsville, MD.

Instituto Adolfo Lutz. 2008. Métodos físico-químicos para análise de alimentos. Coordenadores Odair Zenebon, Neus Sadocco Pascuet e Paulo Tiglea, Instituto Adolfo Lutz, São Paulo, Brasil.

Jacobo-Velázquez, D.A. e L. Cisneros-Zevallos. 2009. Correlations of antioxidant activity versus phenolic content revisited: A new approach in data analysis for food and medicinal plants. J. Food Sci. 74(9), 107-113.

Khademi, O., Z. Zamani, E. Poor Ahmadi e S. Kalantari. 2013. Effect of UV-C radiation on postharvest physiology of persimmon fruit (Diospyros kaki Thunb.) cv. 'Karaj' during storage at cold temperature. Intl. Food Res. J. 20(1), 247-253. (2013)
Marquenie, D., C. W. Michelis, J.F. Impe, E. Scherevens e B.N. Nicolai. 2003. Pulsed white light in combination with UV-C and heat to reduce storage rot of strawberry. Postharvest Biol. Technol. 28, $455-461$.

Mensor, L.L, F.S. Menezes, G.G. Leitão, A.S. Reis, T.C.Santos, C.S. Coube e S.G. Leitão. 2001. Screening of Brazilian plant extracts for antioxidant activity by the use of DPPH $\bullet$ free radical method. Phytotherapy Res. 15, 127-130.

Morgado, C.M.A. 2007. Conservação pós-colheita de abacates 'Geada' e 'Quintal', em diferentes pontos de colheita, com o uso de diferentes temperaturas e proteções. Faculdade de Ciências Agrárias e Veterinárias, Universidade Estadual Paulista, Jaboticabal, Brasil.

Oliveira, M.A. de, C.H. Santos, C.M. Henrique y J.R. Domingos. 2000. Ceras para conservação pós colheita de frutos de abacateiro fuerte, armazenados em temperatura ambiente. Sci. Agric. 57(4), 777 780 .

Perkins-Veazie, P., J. K. Collins e L. Howard. 2008. Blueberry fruit response to postharvest application of ultraviolet radiation. Postharvest Biol. Technol. 47, 280-285.

Pombo, M. A., M. Dotto, G.A. Martinez e P.M. Cive1lo. 2009. UV-C irradiation delays strawberry fruit softening and modifies the expression of genes involved in cell wall degradation. Postharvest Biol. Technol. 51, 141-148.

Sanches J. 2006. Efeito de injuries mecânicas na qualidade pós-colheita de abacates. Tese Doutorado em Produção Vegetal. Faculdade de Ciências Agrárias e Veterinárias, Universidade Estadual Paulista, Jaboticabal, Brasil.

Seymor, G.B. e G.A.Tucker. 1993. Avocado. In: Seymour, G.B., J.E. Taylor e G.A. Tucker (eds.). Biochemistry of fruit ripening. Chapman \& Hall, London.

Singleton, V.L, R. Orthoper e R.M. Lamuela. 1999. Analysis of totalphenols and other oxidation substrates and antioxidants by means of Folin-Ciocalteau reagent. Methods Enzymol. 299, 152-178.

Sricastava, M.P. e N. Sharna. 2013. UV-C Light as an effective physical method to control postharvest diseases. Biol. Chem. Research. 30(2), 354-366.

Stevens, C., J. Liu, V.A. Khan, J.Y Lu, M.K. Kabwe, C.L. Wilson, E.C.K. Igwegbe, E. Chalutz e S. Droby. 2004. The effects of low-dose ultraviolet light treatment on polygalacturonase activity, delay ripening and Rhizopus soft rot development of tomatoes. Crop Prot. 23, 551-554. 
Stevens, C., V.A. Khan, A.Y. Tang e J.Y. Lu.1990. The effect of ultraviolet radiation on mold rots and nutrients of stored sweet potatos. J. Food Prot. 53, 223-226.

Tango, J.S., C.R.L. Carvalho e N.B. Soares. 2004. Caracterização física e química de frutos de abacate visando a seu potencial para extração de óleo. Rev. Bras. Frutic. 6(1), 17-23.

Tressler, D.K. e M.A. Joslyn. 1961. Fruits and vegetables juice processing technogy. Avi Publ. Co., Westport, CT.

USDA (U.S. Department of Agriculture, Agricultural Research Service). 2007. USDA National Nutrient Database for Standard Reference, Release 20. Nutrient Data Laboratory Home Page, http://www.ars.usda.gov/ba/bhnrc/ndl; acesso: junho de 2013.

Vicente, A.R., C. Pineda, P.M. Civello, G.A. Martinez e A.R. Chaves. 2005. UV-C treatments reduce decay, keep quality and alleviate chilling injury in pepper. Postharvest Biol. Technol. 35, 69-78.

Wang, W., R. Terrell e L.G. Bostic. 2010. Antioxidant capacities, procyanidins and pigments in avocados of different strains and cultivars. Food Chem. 122, 1193-1198.

Zauberman, M.S., M. Schiffman-Nadel M. e U. Yanko. 1973. Susceptibility to chilling injury of three avocado cultivars stages of ripening. HortScience 8(4), 511-513. 